\title{
A TRAJETÓRIA DO GT TRABALHO E EDUCAÇÃO DA ANPED: ALGUNS ELEMENTOS DE ANÁLISE
}

\author{
THE TRAJECTORY OF ANPED'S WORK \& EDUCATION WORKGROUP: A FEW ELEMENTS OF \\ ANALYSIS
}

Anita Handfas ${ }^{1}$

Resumo O objetivo do artigo é fazer uma breve reconstituição da trajetória do GT Trabalho e Educação da Associação Nacional de Pós-Graduação e Pesquisa em Educação (Anped), identificando os princípios teóricos que serviram de base para os estudos que buscaram compreender, sob diferentes aspectos, a relação entre trabalho e educação. Para tal, percorro a trajetória de conformação do pensamento educacional crítico brasileiro, notadamente o período de redemocratização do país após o golpe militar de 1964, assim como analiso o contexto político em que se deu a difusão da teoria marxista na pesquisa educacional. Com base em alguns elementos políticos e teóricos identificados neste processo, busco problematizar os limites teóricos dos estudos sobre trabalho e educação que têm como referência a teoria marxista.

Palavras-chave trabalho e educação; pensamento educacional; teoria marxista.
Abstract The purpose of the article is to make a brief reconstitution of the trajectory of the National Association for Post-Graduation and Research in Education Work \& Education's (Anped) Workgroup, identifying the theoretical principles that served as the base for the studies that attempted to understand, from different viewpoints, the work/education relationship. To do so, I cover the path followed by the conformation of the Brazilian critical educational thought, notably the period of re-democratization Brazil went through after the 1964 military coup. Furthermore, I also analyze the political context in which the Marxist theory was disseminated in educational research. Based on a few political and theoretical elements identified in this process, I attempt to problematize the theoretical limits of the studies on work and education that refer to the Marxist theory.

Keywords work and education; educational thought; Marxist theory. 


\section{Introdução}

Completadas quase três décadas de existência, o GT Trabalho e Educação, criado em 1981 na $4^{a}$ Reunião Anual da Associação Nacional de Pós-Graduação e Pesquisa em Educação (Anped), teve sua constituição estimulada pela necessidade de um espaço onde as questões teóricometodológicas, assim como a definição de eixos de pesquisa fossem discutidas ${ }^{2}$. Tal empreitada exigiu dos estudiosos um esforço de elaboração teórica e conceitual capaz de definir as questões que vieram a se constituir em fio condutor da reflexão teórica sobre a temática. Inúmeras foram as condições que marcaram essa trajetória, e é certo que seus efeitos exerceram influência mais ou menos decisiva na consolidação do GT.

Com efeito, estudiosos que protagonizaram aquele momento, o fizeram condicionados por determinadas circunstâncias históricas que, em certa medida, balizaram as possibilidades, mas também os limites para a reflexão e o amadurecimento necessários à elaboração teórica.

Reconstituir essa trajetória é uma tarefa indispensável, quando, depois de um longo tempo de consolidação, se quer apreender o movimento interno do GT Trabalho e Educação, a partir do qual foram estabelecidos os pressupostos que dirigiram a reflexão teórica e que, dentro de certos limites, definiram a problemática em torno da qual os estudos vêm sendo desenvolvidos. Nessa direção, o presente artigo tem o objetivo de traçar o percurso do GT Trabalho e Educação, buscando identificar alguns elementos que possam fornecer pistas para entender a problemática sobre a qual estão assentados os estudos sobre a relação entre trabalho e educação.

Para isso terei necessariamente que levar em consideração o pensamento educacional dentro do qual o campo específico de estudos sobre trabalho e educação se insere. Como se sabe, a conformação do pensamento educacional brasileiro foi marcada de maneira considerável pela influência do referencial teórico marxista, sobretudo no final da década de 1970 e ao longo da década seguinte, quando a retomada da organização dos educadores criou condições mais favoráveis para a difusão do marxismo, por meio da tradução dos escritos de Marx e de outros pensadores marxistas e, posteriormente, com a produção teórica educacional de autores marxistas brasileiros.

Como buscarei demonstrar, a investigação dessa trajetória revelará os elementos que determinaram as possibilidades e os limites impostos aos estudiosos marxistas na análise dos processos educacionais. Será útil também para compreender as formas de inserção da teoria marxista no pensamento educacional, permitindo articulá-las aos estudos que tratam especificamente da relação entre trabalho e educação. 
Primeiramente analisarei a trajetória do pensamento educacional, focalizando mais especificamente a difusão da teoria marxista e os princípios teóricos sobre os quais a produção teórica educacional marxista se desenvolveu nesse processo. Em seguida, identificarei a maneira pela qual os principais elementos que caracterizaram a trajetória de inserção da teoria marxista no pensamento educacional incidiram no próprio percurso histórico de constituição do GT Trabalho e Educação.

\section{A difusão da teoria marxista no pensamento educacional brasileiro}

A reorganização do campo educacional no Brasil, cuja presença do elemento político foi marcante, sofreu os influxos dos acontecimentos políticos que marcaram a articulação do meio intelectual em geral.

A ocorrência de eventos de natureza acadêmica e política, a criação das entidades nacionais, e com elas a reativação editorial, assim como a implantação da pós-graduação em educação são os principais acontecimentos que favoreceram a organização do campo educacional.

O marco dessa organização deu-se em 19783, com a realização do I Seminário Brasileiro de Educação, sucedendo-se as demais edições bienais já transformadas, a partir do II Seminário, nas Conferências Brasileiras de Educação (CBEs). É importante destacar o caráter político desses eventos. Em sintonia com a rearticulação do meio intelectual que então se processava, todo o esforço girava em torno da tentativa de superar o momento de crítica para inaugurar o momento das proposições.

Esses eventos só foram possíveis graças ao surgimento de entidades que congregaram os educadores em nível nacional, que, em conjunto, passaram a promover as CBEs, conferindo a estas um caráter de oposição ao regime ditatorial. Criadas com o objetivo de desenvolver atividades de estudos, essas entidades tinham em comum a crítica à educação brasileira e a afirmação de bandeiras de interesse da grande maioria da população na luta pela escola pública e gratuita.

Dentre essas entidades, o Centro de Estudos Educação e Sociedade (Cedes), criado em 1979, e a Associação Nacional de Educação (Ande), criada no mesmo ano, foram espaços importantes de reorganização dos educadores.

A realização desses eventos e o surgimento dessas entidades favoreceram também a profusão de publicações na área educacional, como a $R e-$ vista Educação \& Sociedade, criada em 1978 e ainda hoje considerada referência na área. Sua repercussão no meio educacional foi tamanha que teria estimulado seus organizadores a fundar o Cedes, que passou a editar posteriormente os Cadernos Cedes, o qual deixou de ser publicado. Ainda no 
âmbito dos periódicos, deve ser registrada também a Revista da Ande, que contemplava a produção educacional crítica que naquele momento buscava se consolidar.

Outra entidade que desempenhou papel decisivo, no que diz respeito à produção teórica do campo educacional, foi a Associação Nacional de PósGraduação e Pesquisa em Educação (Anped). Criada em 1978, veio coroar o processo de estruturação da pós-graduação stricto sensu na área educacional, que teve início em 1965, com o programa de mestrado da Pontifícia Universidade Católica (PUC) do Rio de Janeiro. A Anped veio somar-se às demais entidades que se constituíram em espaços de reorganização dos educadores, dando sustentação acadêmica e política ao movimento de crítica à política educacional que então se iniciava, expressando de algum modo a tentativa de impor a todo esse movimento o rigor teórico e a autonomia necessários à produção do conhecimento.

Esse processo impulsionou a produção teórica na área educacional por meio dos periódicos, pela profusão de literatura específica da área e também por meio da tradução para a língua portuguesa de autores importantes que investigavam a questão educacional a partir de diferentes enfoques. Ficam disponíveis então aos pesquisadores brasileiros autores com diferentes perspectivas teóricas, como Célestin Freinet, Maria Tereza Nidelcoff, Ivan Illich, Pierre Bourdieu, Jean Claude Passeron, Roger Establet e Christian Baudelot, Louis Althusser, George Snyders, Mario Manacorda, entre os principais. Paulo Freire também deve ser incluído nesta relação, na medida em que, mesmo sendo brasileiro, é considerado, juntamente com os demais, um autor que passou a figurar como referência teórica, especialmente no que diz respeito aos estudos sobre a educação popular.

Outro fato que merece destaque é o incremento de títulos brasileiros sintetizando as reflexões dos educadores 4 , o que indica o esforço empreendido pelos pesquisadores brasileiros em estudar a realidade educacional de forma crítica, numa tentativa de analisar os fenômenos educacionais aplicando a teoria às condições concretas e objetivas da realidade.

Essa farta produção que passou a ser socializada aos pesquisadores por meio das publicações foi resultado das pesquisas desenvolvidas pelos estudantes de pós-graduação que então estava em pleno processo de crescimento. Num espaço de apenas uma década, entre 1960 e 1970, a pós-graduação em educação acumulou cerca de trinta cursos, primeiramente de mestrado e, a partir de 1976, de doutorado.

A década de 1970 veio marcar uma nova fase da pós-graduação que sucedeu outra, caracterizada pelo predomínio de temas econômicos 5 e o patrocínio de agências governamentais e internacionais. Havia um contexto que, somado à dinâmica de reorganização dos educadores desde o início da década de 1960 e respaldado a partir de então pelas condições favoráveis da 
pesquisa educacional, estimulou o pensamento crítico. A crítica ao Estado ditatorial e às políticas educacionais, consoante com o movimento de resistência entre os intelectuais, assim como a reorganização dos educadores em torno das entidades foram os fatos que caracterizaram aquele período.

Dadas as circunstâncias de organização e de desenvolvimento da pós-graduação em educação, é possível, então, refletir sobre as possibilidades e os limites postos aos pesquisadores, no que diz respeito à produção teórica, assim como à própria natureza do pensamento crítico que então se processava.

O contexto político da época, caracterizado por um regime ditatorial, enfrentou processos de resistência resultando, na segunda metade da década de 1970, no surgimento de um novo pensamento social de oposição, reclamando-se de esquerda. No tocante à produção de conhecimento, o esgotamento do regime ditatorial, a partir do final da década de 1970, impulsionou a produção teórica de natureza crítica. Tanto nas instituições de pesquisa como na universidade, esses estudos centravam-se em temáticas econômico-sociais, tendo no discurso da ditadura o alvo de sua crítica.

No que diz respeito ao pensamento educacional, à medida que se aprofundava a crise da ditadura, o processo de resistência tendia a se acelerar. Impulsionada pela reorganização dos educadores, a partir dos anos 80 , a reflexão crítica sobre a educação brasileira emerge, dada a urgência na transformação do ensino, bem como das práticas pedagógicas. Tal reorganização deu-se sob o crivo da participação crescente dos movimentos sociais, motivando a articulação política dos educadores com esses movimentos.

Não resta dúvida que a produção teórica de natureza crítica que então buscava se consolidar assinala um importante avanço, sobretudo no que diz respeito à superação da política cultural e educacional de obstrução dos canais entre a universidade e os movimentos sociais implantada pela ditadura. Além disso, a própria natureza da produção teórica buscava superar o predomínio dos estudos sem qualquer historicidade, estabelecendo os nexos entre os fenômenos educacionais e as demais instâncias da sociedade, remontando à gênese e às condições sociopolíticas da educação brasileira.

Entretanto, não se pode subestimar os efeitos da intervenção da ditadura na tão incipiente tradição marxista no Brasil, que, a despeito do acúmulo de uma produção teórica marxista original que vinha se processando, passou a enfrentar condições desfavoráveis à sua continuidade, tendo em vista o golpe militar de 1964.

Tais circunstâncias trouxeram conseqüências para o processo de elaboração teórica crítica de inspiração marxista. E ainda que seus efeitos tenham se manifestado de forma particular em cada um dos espaços em que o debate teórico marxista se dava, o âmbito acadêmico, mais especificamente os programas de pós-graduação, onde se concentraram os estudos e as 
pesquisas educacionais, não foi uma exceção. À trajetória de um insuficiente acúmulo do pensamento marxista correspondeu uma retomada dos estudos, cujas condições para o trabalho teórico não se encontravam ainda totalmente à disposição dos estudiosos.

Vejamos de que maneira o contexto apresentado se manifestou especificamente na produção teórica proveniente dos programas de pós-graduação em educação. É o que será feito no próximo item.

\section{Formas de inserção da teoria marxista na pesquisa educacional}

Sem perder de vista o pano de fundo que marca o contexto de difusão da teoria marxista no pensamento educacional, tentarei reconstituir os principais eventos que marcaram a trajetória da produção teórica marxista na pósgraduação em educação, focalizando especificamente o Programa de PósGraduação em Educação da PUC de São Paulo. Tal escolha não é aleatória, mas deve-se ao fato de ele ter criado, em função da conjunção de uma série de fatores, um ambiente propício à formação de um pensamento crítico, especialmente em sua primeira turma de doutorado.

Antes de traçar os principais eventos de sua trajetória, é importante frisar que o fato da pós-graduação em educação ter desempenhado um papel fundamental na reorganização política e acadêmica dos educadores e representado um avanço em sua consciência crítica não deve ser confundido com a sua capacidade orgânica de formulação crítica sustentada no referencial teórico marxista. Nem mesmo o Programa de Pós-Graduação em Educação da PUC-SP, que reuniu nomes de expressão que buscavam empreender uma crítica consistente e rigorosa à política educacional, constituiu-se em sua origem a partir desse referencial teórico, tampouco seus professores e alunos integraram o programa em virtude disso.

É fundamental partir desse a priori para que se possa verificar adequadamente as condições em que a crítica educacional foi realizada, de modo a não dimensioná-la de forma abstrata, nem frustrar expectativas decorrentes de uma superestimação das possibilidades da crítica científica dadas naquele contexto. Se as condições políticas e teóricas daquele momento determinaram os limites e as possibilidades impostos aos pesquisadores, é possível, então, identificar a natureza da crítica que começava a ser formulada. Pensar, tal como fazem alguns autores, que a pós-graduação em educação da PUC-SP era um pólo de irradiação do marxismo pode levar a conclusões precipitadas, avaliando, tanto positiva como negativamente, as formas de difusão da teoria marxista no pensamento educacional.

O Programa de Pós-Graduação em Educação da PUC-SP surgiu em 1969 com o curso de mestrado em Psicologia da Educação. Somente em 1971 pas- 
sou a ser denominado Programa de Estudos Pós-Graduados em Filosofia da Educação, favorecendo a criação, alguns anos mais tarde, em 1977, do curso de doutorado.

Já em 1978, sob a coordenação de Dermeval Saviani, o programa foi se consolidando em torno da idéia de que, passada a fase da denúncia políti$\mathrm{ca}$, era hora de assumir uma postura mais propositiva, o que correspondia a uma 'inversão do sinal'. Essa idéia se fundava no imperativo que se tinha em articular a teoria e a prática, isto é, no entendimento de que não era possível separar a ação institucional do trabalho teórico-acadêmico.

Entre a maioria dos pesquisadores que congregavam a pós-graduação da PUC-SP, predominava a posição de que se deveria buscar uma intervenção no interior do Estado e no direcionamento das políticas educacionais e uma participação ativa nos espaços institucionais, concebendo-se a própria inserção dos educadores e, como decorrência, a organização do espaço pedagógico como os elementos fundamentais para a construção da teoria pedagógica e para a realização da ação pedagógica.

$\mathrm{O}$ espaço pedagógico a que se referiam os educadores era o espaço escolar, considerado como o local por excelência da prática pedagógica do educador. E é para a escola pública que as atenções se voltavam, já que nela que era educada a maioria dominada da população. Portanto, era a escola que necessitava ser organizada. Daí a necessidade de os educadores desenvolverem-se teoricamente não só como um guia para a ação, mas, sobretudo, para a elaboração de uma teoria da educação brasileira.

Num livro em que busca resgatar a trajetória do Programa de PósGraduação em Educação da PUC-SP, Ribeiro (1987) constatou a existência de um ambiente profícuo para a reflexão dos fenômenos educacionais. Havia um forte interesse na compreensão dos problemas educacionais, o que teria levado o grupo a perceber a importância do aprofundamento teórico para isso. Percebe-se, entretanto, que não havia acúmulo suficiente que permitisse imprimir a consistência teórica necessária ao trabalho de produção do conhecimento. O que se contava, na realidade, era com a iniciativa individual de algumas pessoas que, por circunstâncias de sua própria formação, já tinham tido mais ou menos acesso a autores do campo marxista, ou às leituras do próprio Marx 6 .

Essa condição foi evidenciada também por Yamamoto (1994), que reuniu uma série de depoimentos de alguns dos principais protagonistas do Programa de Pós-Graduação de Educação da PUC-SP. Neles é possível constatar as condições em que os estudos eram implementados e dimensionar o insuficiente acúmulo teórico existente entre os pesquisadores, não só do ponto de vista da leitura de textos marxistas, mas, sobretudo, das condições para a sua assimilação. 
As condições para a formação de um pensamento crítico no campo educacional não se constituem em um fenômeno isolado, devendo ser compreendidas à luz do contexto social e político de um dado período e do próprio acúmulo do pensamento marxista no Brasil. Nesse sentido, é importante identificar as formas particulares de intervenção de alguns elementos desse contexto que determinaram uma dinâmica própria de formação do pensamento educacional crítico.

Um dos elementos que identifiquei é a presença da 'sobrepolitização' na análise dos processos educacionais. Do ponto de vista teórico, ela se manifestou nas formas idealizadas e ahistóricas de investigar a realidade educacional, priorizando as formas práticas de atuação, em detrimento do trabalho de elaboração teórica e conceitual. Devemos lembrar que aquela conjuntura propiciou um certo clima de euforia entre os educadores que então retomavam sua organização, o que pode tê-los levado a superdimensionar o potencial de ocupação dos espaços institucionais, avaliando poder interferir de forma propositiva nas políticas educacionais. A urgência imposta por essa estratégia pode ter provocado uma subestimação do trabalho teórico que requer, necessariamente, tempo e preparação para longos e complexos estudos.

Vários foram os efeitos desse processo. Um deles foi a substituição do exame das matrizes originais da teoria marxista pelos seus comentaristas. Havia, inclusive, a consideração de que a leitura da obra de Marx era extremamente difícil e, por conseguinte, o receio em enfrentá-la7.

Uma das possíveis conseqüências desse fato foi a adoção de uma visão instrumental de trabalhar a teoria e a exaltação da crítica abstrata, na medida em que o sistema conceitual variava ao sabor da conjuntura educacional e não das exigências imanentes da reflexão. Além do mais, e aqui vemos claramente de que maneira operava a 'sobrepolitização', a avaliação do passado era posta sem a consideração concreta dos condicionantes históricosociais e políticos que sobre ele incidiram.

Outro modo de manifestação desse enfoque instrumental decorre de uma certa leitura dos textos marxistas que, ao invés de deter o pensamento do autor em sua totalidade, retém do texto somente aquilo que se ajusta à análise. Este procedimento é prejudicial às investigações dos processos educacionais, justamente porque elas tendem a perder de vista os condicionantes histórico-sociais de contextos específicos a que se referem, além de desconsiderar as circunstâncias políticas e ideológicas em que o texto foi escrito.

É importante destacar, ainda, mais um componente desse processo que se manifestou de modo específico na pesquisa educacional. Trata-se da maneira como foram lidos e interpretados os pensadores do campo marxista. Podemos tomar como exemplo dois autores bastante difundidos 
que exerceram forte influência na pesquisa educacional. Trata-se de Louis Althusser e Antonio Gramsci.

É comum ocorrer na produção teórica educacional a associação das circunstâncias conjunturais de um contexto específico à aproximação com pensadores marxistas. Neste caso, a conjuntura determi naria o emprego do sistema teórico e conceitual de um ou outro autor, na medida em que eles fossem úteis para a compreensão da realidade. Uma vez que as circunstâncias se modificassem, outros autores ganhariam destaque.

No plano do trabalho científico, este procedimento pode comprometer o processo de investigação. Isto porque, dessa forma, as teorias tornam-se reféns da dinâmica conjuntural, sendo enaltecidas ou descartadas, em vez de se de constituírem no núcleo central através do qual a reflexão sobre a realidade deve ser conduzida.

Inúmeros autores analisaram as formas de difusão do pensamento de Althusser e de Gramsci no Brasil e forneceram algumas indicações da maneira pela qual esses autores foram assimilados pelos estudiosos 8 .

Althusser passou a exercer forte influência no pensamento educacional a partir do início da década de 1970, período que coincide com aquele caracterizado pelos educadores como o de resistência ao regime ditatorial no Brasil. Como vimos, os depoimentos recolhidos por Yamamoto (1994) atestam que as mudanças políticas por que passava a sociedade brasileira, já em meio à década de 1970, impunham um novo tipo de intervenção prática e teórica na realidade educacional. Segundo as palavras de Cury (1981, p. 163), "passado o momento mais enfático de negação, há que aprofundar os caminhos da negação da negação, isto é, uma firmação qualitativamente superior da educação na realidade brasileira".

Na pesquisa educacional, o estudo de Althusser incidiu principalmente sobre a leitura dos Aparelhos ideológicos de Estado, obra em que o autor analisa as formas de dominação ideológicas das diferentes instâncias do Estado. Como se sabe, esta era uma leitura obrigatória entre os estudiosos, pelos elementos que o texto poderia fornecer para compreender os mecanismos de reprodução da ideologia burguesa no interior da escola. Entretanto, já em meados da década de 1970, tendo em vista a avaliação sobre o processo de democratização do país e a estratégia de intervenção dos educadores nos espaços institucionais, o interesse começa a se voltar para a leitura de Gramsci.

Analisando a influência do pensamento de Gramsci entre os educadores brasileiros, Nosella (1992) salientou que, a partir de 1978, os estudos desse autor desenvolveram-se de forma mais sistemática entre os alunos da primeira turma de doutorado do Programa de Pós-Graduação em Educação da PUC-SP. Entretanto, para ele, o empenho dos pesquisadores na leitura da 
obra de Gramsci e de seus comentadores não foi suficiente para que ocorresse uma assimilação profunda do pensamento do autor.

Nosella identificou a ausência de uma contextualização histórica dos textos gramscianos, o que teria resultado na apreensão abstrata e doutrinária das categorias formuladas por Gramsci9.

O uso de teorias distintas em função da dinâmica da conjuntura aponta para um processo analítico caracterizado pela abordagem superficial da teoria. Isso explica a aproximação e o descarte de teorias, sem que se dispusesse do tempo de reflexão e amadurecimento necessários para a apreensão crítica do pensamento do autor.

Um dos efeitos desse tipo de procedimento é o impulso em qualificar, dentro de certos limites, um ou outro autor. Assim, temos, entre aqueles estudiosos que se ocuparam em analisar o impacto de diferentes teorias na pesquisa educacional, a tendência a designar o pensamento de Althusser como 'reprodutivista', ou associar Gramsci ao teórico da superestrutura.

Como se sabe, Antonio Gramsci formulou um sistema conceitual bastante complexo, na medida em que, associado ao elemento político, fosse capaz de apreender a realidade sob todos os seus aspectos e em todas as suas dimensões. Dessa forma, ao enfrentar os temas que foram objeto de sua reflexão, ele buscou estabelecer os vínculos com as questões políticas de seu tempo, investigando as experiências históricas, tendo em vista a ação e a possibilidade efetiva da intervenção das classes subordinadas no processo histórico. Portanto, me parece que qualificar Gramsci como o teórico da superestrutura acaba por limitar todo o alcance de sua formulação teórica.

Esta observação é válida também para o termo 'reprodutivista'. Na década de 1960, Louis Althusser, juntamente com um grupo de pesquisadores, realizou um estudo crítico da obra de Marx. Para isso, a partir da releitura de $O$ capital, trouxe à tona o debate de questões teóricas e filosóficas concernentes ao marxismo. Uma das questões sobre a qual o grupo se ocupou foi o estudo da reprodução social de um modo de produção, o que implicava necessariamente analisar a dinâmica de reprodução e de transição de um modo de produção para outro.

Há ainda um outro elemento que deve ser considerado. Tendo em vista os problemas apontados em relação à leitura de Marx e de Gramsci, podemos indagar até que ponto os estudiosos acabaram por fazer uma leitura de Marx, sob a ótica de Gramsci. Tal procedimento é problemático, pois ele impede a apreensão do pensamento tanto de um como de outro autor, como impede também o conhecimento das diferenças teóricas entre esse dois pensadores.

Em linhas gerais, estes foram os principais eventos que marcaram a reorganização do campo educacional no Brasil e forneceram as condições para a difusão da teoria marxista no pensamento educacional. Esse breve re- 
trospecto nos indica que o esforço empreendido pelos educadores esbarrou em dificuldades objetivas do contexto político que caracterizou aquele período, assim como sofreu os influxos da própria dinâmica de evolução do pensamento marxista no Brasil.

No item a seguir buscarei mostrar de que maneira esses elementos repercutiram na produção teórica sobre trabalho e educação.

\section{Condições históricas da produção teórica sobre trabalho e educação}

Como se observa no percurso traçado até aqui, por ter sido alavancada em pleno contexto de implementação das políticas educacionais do regime militar, a pesquisa educacional teve uma influência considerável do pensamento crítico, em particular do pensamento marxista. Com efeito, o grupo de pesquisadores que formaram o núcleo em torno do qual se concentraram as discussões concernentes à relação entre trabalho e educação também buscava sistematizar de forma crítica suas principais concepções teóricas.

Nessa direção, vale retomar as considerações de Trein e Picanço a respeito do percurso do GT Trabalho e Educação da Anped. Segundo as autoras, esse campo de pesquisa "vem se construindo menos como um recorte no campo educacional e mais como a busca da elaboração teóricometodológica que auxilie na compreensão da formação humana" (Trein e Picanço, 1995, p. 89).

Isso significa que o próprio processo de constituição desse campo específico de pesquisa educacional resultou da definição dos pressupostos teóricos que conduziram as análises concernentes à relação entre trabalho e educação. Dizer que o campo se conformou na busca de uma elaboração teórica para compreender a formação humana já define a problemática a partir da qual os pesquisadores operaram com a teoria marxista.

Podemos apontar a crítica à teoria do capital humano como um dos principais elementos para a fundamentação teórica do GT Trabalho e Educação. Kuenzer (1991) situa a década de 1960 como o período de consolidação da teoria do capital humano no Brasil, dado o correspondente estágio de desenvolvimento do capitalismo. As condições históricas desse período, caracterizado pelo acirramento da subordinação da burguesia nacional aos interesses do capital financeiro internacional, permitiram a veiculação e a consolidação dos pressupostos teóricos do capital humano, assim como propiciaram às classes dominantes um terreno fértil para a veiculação de mecanismos ideológicos capazes de sedimentar a ilusão do mérito individual para a ascensão social.

Sob a égide da racionalização e da segurança nacional, as classes dominantes implementaram uma série de medidas visando o controle social. No 
campo educacional, essas medidas foram tomadas sob o pretexto de dotar o sistema de ensino de maior racionalidade.

Do ponto de vista da produção teórica, a pesquisa educacional no Brasil sofreu influência marcante da teoria do capital humano, sobretudo os estudos que tratavam, sob diferentes aspectos, da relação entre educação e trabalho. Tal influência foi decorrente da própria formação dos pesquisadores brasileiros, em grande parte realizada nos EUA, devido à insuficiência de cursos de pós-graduação no Brasil. Adotando o empirismo como método de investigação, esses estudos buscaram na produção dos teóricos do capital humano o embasamento para a fundamentação, cuja hipótese central era formulada a partir da relação entre educação e desenvolvimento econômico e social.

Começam a se delinear então duas direções opostas, no que diz respeito à análise dos processos educacionais. Por um lado, a idéia de que, concebendo a educação como um fator social, supunha poder ajustar os processos educacionais às demandas de acumulação do capital; por outro, uma concepção que, rejeitando o tecnicismo educacional, buscava formular um projeto político-pedagógico mais democrático e voltado aos interesses das classes trabalhadoras.

Esse processo de crítica à economia da educação iniciou-se em meados da década de 1970. Inúmeros estudos concentraram-se na análise dos processos educacionais a partir de diferentes enfoques, tendo em vista a crítica aos pressupostos da teoria do capital humano.

Com efeito, o alvo da crítica não se concentrou apenas nas concepções então dominantes. Ele direcionou-se também às teorias educacionais que se situavam igualmente no campo crítico da reflexão educacional. O debate no interior do próprio campo educacional crítico ocorreu em função de um certo acúmulo de reflexão decorrente de um processo que vinha se desenvolvendo com a elaboração de alguns estudos críticos. Além disso, não podemos esquecer que essa fase coincide com o período em que os educadores avaliavam que as condições políticas instauradas no país com a democratização exigiam deles uma postura teórica e prática mais propositiva.

Por esse motivo, vale ressaltar que o embate teórico no interior do próprio campo crítico vai expressar naquele momento o predomínio de uma concepção teórica a respeito dos processos educacionais e, particularmente, do papel transformador da escola, cujos pressupostos se chocavam com os dos estudos críticos que vinham sendo até então elaborados.

Esse duplo movimento de crítica se insere no processo de elaboração teórica que veio inaugurar uma nova fase no pensamento educacional marxista e, em particular, nos estudos que analisavam a relação entre trabalho e educação. 
A questão central que instigava o debate girava em torno da relação entre educação e estrutura econômico-social e. como decorrência, da definição das funções da escola na sociedade capitalista.

Vale lembrar que data desse mesmo período o surgimento de algumas obras que tiveram repercussão importante no pensamento educacional crítico. Trata-se dos estudos de Luis Antonio Cunha (1975), que escreveu Educação e desenvolvimento social no Brasil; Wagner Gonçalves Rossi (1978), autor do livro Capitalismo e educação; de Maria Luiza dos Santos Ribeiro (1978), que escreveu História da educação brasileira; de Mirian J. Warde (1979), autora de Educação e estrutura social; e ainda, Barbara Freitag (1980), com Escola, Estado e sociedade e Cláudio Salm (1980), com Escola e trabalho.

Esses estudos tiveram o mérito de empreender pela primeira vez uma reflexão crítica dos processos educacionais, buscando em autores marxistas (e, em alguns casos, não se restringindo a eles) o referencial teórico de análise. Entre eles, o trabalho de Rossi (1980)10, primeiro a estabelecer os vínculos entre trabalho e educação, que analisa os mecanismos de utilização da escola como instrumento ideológico nas mãos do capital, para garantir uma formação compatível com os interesses do sistema, e discute o significado da escola capitalista, confrontando sua visão com as concepções educacionais, denominadas por ele conservadoras, liberais, reformistas e revolucionárias. O fio condutor de sua análise é a crítica ao 'pedagogismo' ou 'messianismo pedagógico', sobretudo na sua manifestação mais evoluída, a teoria do capital humano.

Em outra direção, mas também numa perspectiva crítica, o estudo de Salm (1980) buscou empreender a crítica tanto às concepções burguesas da economia neoclássica como às de Rossi, que, de acordo com Salm, enfatizariam o vínculo entre produção e educação. Nesse sentido o autor sustenta a tese de que o sistema capitalista pode prescindir da escola, já que a qualificação do trabalhador se daria no interior do próprio sistema produtivo.

Vimos que o grupo de pesquisadores reunidos no doutorado do Programa de Pós-Graduação em Educação da PUC-SP desempenhou um papel de destaque na produção teórica educacional crítica. Dessa forma, o debate em torno das diferentes concepções teóricas enunciadas teve em grande medida o protagonismo desses estudiosos.

Este debate, assim como as principais proposições dos pesquisadores foram formuladas por Frigotto (1999). Para este autor, por um lado, não se poderia atribuir à escola o papel de oferecer as condições necessárias para o crescimento dos indivíduos, como se não houvesse antagonismos na sociedade capitalista, como preconizavam os teóricos do capital humano. Por outro, não se poderia conceber a escola como locus exclusivo de reprodução das relações sociais capitalistas, como argumentavam os 'crítico-reprodu- 
tivistas', rótulo que passou a ser corrente entre os seus críticos. Finalmente, tampouco a escola deveria ser concebida como um elemento independente da base material da sociedade, conforme afirmou Salm (1980).

Em direção contrária, os críticos argumentavam que não obstante a existência do vínculo entre educação e processo produtivo, tal vínculo não poderia ser concebido de forma mecânica, mas de forma indireta e mediata, o que significaria considerar a educação como uma prática contraditória e, portanto, articulada tanto aos interesses da classe dominante, como aos da classe dominada.

O processo de crítica à teoria do capital humano foi delimitado pelo debate em torno do estabelecimento da relação entre educação e estrutura econômico-social e se situa num momento preciso da história da constituição do marco teórico do GT Trabalho e Educação, a saber, entre o final da década de 1970 e o início da década de 1980.

A análise desse processo possibilita constatar a ocorrência de dois níveis de crítica: a crítica à teoria do capital humano e a crítica das críticas à teoria do capital humano. Mais precisamente, é possível afirmar que a crítica à teoria do capital humano mobilizou esforços para a crítica às teorias que analisaram a escola tendo em vista a reprodução social e ideológica e, em decorrência, para a elaboração de uma concepção teórica que acabou por prevalecer no interior desse campo de estudos.

Sem nenhuma pretensão de aprofundamento, essas são as principais questões teóricas em torno das quais se deu o debate entre os estudiosos do campo de trabalho e educação, tendo em vista a formulação de uma teoria marxista que estabelecesse os vínculos entre trabalho e educação.

A seguir serão explicitados os pressupostos teóricos que serviram de base para os estudos sobre trabalho e educação. Nesse item farei algumas considerações a partir da identificação de alguns elementos presentes nesses estudos.

\section{Pressupostos teóricos da relação entre trabalho e educação}

Um evento importante do GT que pode indicar a concepção teórica que o informou foi a inversão da denominação Educação e Trabalho para Trabalho e Educação.

Tal inversão foi justificada por Kuenzer, ao mostrar que

“(...) a área estava padecendo de uma inversão ao tomar a educação como ponto de partida para a análise. Retomando-se os princípios fundamentais da crítica à economia política, concluiu-se que o que distingue esta área temática de outras no campo geral de educação é o fato de que nesta, a dimensão trabalho constituiu-se como categoria central da qual se parte para a compreensão do fenô- 
meno educativo e das articulações recíprocas entre estas duas dimensões educação e trabalho. Reconhecer que o trabalho, na organização da sociedade é o princípio educativo primeiro, é fundamental para superar a concepção burguesa da relação entre educação e trabalho, na qual a escola deverá articular-se com o trabalho como estratégia de socialização e qualificação do trabalhador, tendo em vista as necessidades postas pelas relações capitalistas, com toda a sua dinamicidade" (Kuenzer, 1991, p. 92).

O pressuposto central a partir do qual os estudos se valeram foi o de que o trabalho é o princípio educativo do homem. O homem se forma e se educa pelo trabalho, que adquire determinadas características de acordo com um modo de produção específico. Por ser seu elemento de formação, o trabalho é a própria essência do homem.

Sabemos quais são os mecanismos ideológicos empregados pela burguesia para justificar as desigualdades sociais e que na educação essa ideologia se expressa na teoria do capital humano. Nesse sentido, verifica-se que a inversão dos termos do campo de estudos de trabalho e educação teve o intento de criticar as concepções da economia política burguesa, segundo as quais a educação era uma via para o crescimento individual e para o desenvolvimento econômico e social do país.

Para contrapor-se às concepções dos teóricos do capital humano, seus críticos tiveram como base o conceito de alienação. O problema central que conduziu a crítica estava na suposição de que a forma ahistórica da concepção burguesa de apresentar a realidade reduziria as noções de homem, trabalho e educação a uma esfera abstrata e desprovida de suas determinações históricas e sociais. Isso porque a sociedade capitalista provocaria a perda daquilo que representa o próprio substrato do devir humano, sua capacidade de produzir suas condições de existência e, ao mesmo tempo, de produzir-se a si mesmo, capacidade essa que se configura em fundamento do conhecimento humano e em princípio educativo.

A não historicidade da análise burguesa da sociedade se manifestaria, segundo seus críticos, na forma indeterminada de se referir ao homem como se este fosse dotado de certas faculdades imutáveis, uma vez que seriam inerentes à sua própria natureza. Por esse caminho os teóricos do capital humano buscariam justificar a lógica do sistema de organização econômica do capitalismo baseada num mercado em concorrência perfeita. O que moveria o funcionamento da sociedade seria a racionalidade e o egoísmo do homem. Assim, a troca e a divisão do trabalho, por exemplo, resultariam simplesmente do desejo das pessoas em satisfazerem suas necessidades.

Em contraposição, os críticos argumentavam que a concepção burguesa abstrata e ahistórica da sociedade ocultaria uma realidade muito mais complexa que, para além de resultante de comportamentos individuais, seria 
determinada por relações sociais entre classes antagônicas. No capitalismo, essas relações seriam determinadas pela cisão entre os proprietários e os não proprietários dos meios de produção, condição essa que seria a causa da alienação do trabalhador, seja pelo fato de que ele deixa de se reconhecer nos produtos de seu trabalho, seja pelo fato de que a sua inserção no processo de produção se dá sob a degradação das suas condições materiais.

Com base nessas considerações foi desencadeado o processo de delimitação do marco teórico do GT Trabalho e Educação, que teve na noção de trabalho seu principal fundamento. Nesse sentido, a contradição encerra-se entre a noção burguesa de trabalho que, buscando naturalizar as relações sociais existentes no capitalismo, transforma-o em simples objeto, e a concepção segundo a qual o trabalho transcende a perspectiva pedagógica para constituir-se na própria essência do homem.

Sob essa ótica, o foco de análise é deslocado da relação em que a educação assume o papel de preparação para o mercado de trabalho para uma dimensão em que o trabalho é o elemento que caracteriza a própria existência humana, ou seja, o homem se educa em contato com a natureza por meio da aquisição do conhecimento e da consciência no processo de produção de sua existência.

Podemos observar essa problemática por meio do emprego de algumas noções, quando se estabelece a relação entre trabalho e educação, o trabalho adquire a primazia na medida em que ele representa o fundamento do processo de elaboração do conhecimento. O processo de produção do saber se dá no confronto do homem com a natureza e nas relações sociais travadas em cada época histórica.

No plano da filosofia, cabe observar que o uso da noção genérica de trabalho origina-se da relação especular estabelecida entre o homem e o objeto de seu trabalho e todos os efeitos de alienação resultantes dessa relação.

É importante problematizar algumas questões que decorrem da definição dos pressupostos teóricos desse campo de estudos e que motivaram a inversão do Grupo de Trabalho da Anped para Trabalho e Educação.

A primeira questão diz respeito à própria noção de trabalho, empregada aqui de forma genérica como categoria determinante em sua relação com a educação.

Uma observação a esse respeito foi feita por Tumolo (1997). Ele analisou criticamente a bibliográfica sobre o tema da reestruturação produtiva no Brasil e chamou a atenção para alguns problemas teóricos e metodológicos que impedem a apreensão do fenômeno em todas as suas determinações, identificando o limite dos estudos que trazem como referencial de análise o trabalho concreto, na medida em que abstraem o processo de trabalho de sua subordinação à lógica capitalista. 
Em outro texto, Tumolo (1997) identificou essa mesma tendência nas pesquisas que tratam da relação entre trabalho e educação e salientou que é preciso "pensar o fenômeno educacional no bojo do novo padrão de acumulação de capital que vem se gestando e se consolidando - a 'acumulação flexível' - que se expressa através dos mais variados modelos de produção ou processos de trabalho".

Podemos notar os obstáculos encontrados nos estudos que empregam a idéia genérica e abstrata de trabalho, quando verificamos a maneira pela qual Marx analisou a sociedade capitalista. Na obra deste autor, noções como trabalho só adquiriram sentido na medida em que foram empregadas como conceitos que permitiram compreender a realidade investigada. Assim, a noção de trabalho apresenta-se como um conceito quando articulada à força de trabalho, trabalho concreto, trabalho abstrato etc. No plano da análise social, isso corresponde a dizer que, para pensar a natureza do trabalho, Marx o fez pelas condições sociais de seu emprego.

Em sua análise do Programa do Partido Operário Alemão, Marx fez uso desse sistema conceitual. No que diz respeito ao enunciado de que "O trabalho é a fonte de toda a riqueza e de toda a cultura", ele afirmou que

“O trabalho não é a fonte de toda a riqueza. A natureza é a fonte dos valores de uso (que são os que verdadeiramente integram a riqueza material!), nem mais nem menos que o trabalho, que não é mais que a manifestação de uma força natural, da força de trabalho do homem. Essa frase encontra-se em todas as cartilhas e só é correta se se subtender que o trabalho é efetuado com os correspondentes objetos e instrumentos. Um programa socialista, porém, não deve permitir que tais tópicos burgueses silenciem aquelas condições sem as quais não têm nenhum sentido" [grifos da autoral (Marx, 1961, p. 211).

A alusão aos meios de trabalho - objetos e instrumentos - e às condições em que o trabalho é realizado indica a maneira pela qual Marx fez intervir os conceitos, diferenciando-se da concepção burguesa que confere ao trabalho uma "força criadora sobrenatural". Essa é, inclusive, a única via de superação do emprego de noções abstratas e genéricas na análise dos fenômenos sociais.

O problema da sistematização conceitual no marxismo remete à questão da historicização das categorias, assinalada por diversos autores como sendo a linha de demarcação do marxismo com relação a outras correntes teóricas. Uma das características centrais da teoria marxista, no que diz respeito ao seu método científico, é a sua capacidade de conduzir a investigação levando em conta as condições específicas de cada formação social.

Nesse sentido, é preciso refletir também sobre o problema da historicização das categorias, supondo-se ser este um meio de afastar-se do 
geral para ir ao concreto da realidade investigada. A questão que se coloca é que, ao ser ignorada a função do sistema conceitual que forma a teoria marxista, pode-se acabar restringindo a historicização a uma contextualização histórica, no sentido de considerar os fatos históricos sem, contudo, compreendê-los em sua articulação com as demais instâncias da sociedade.

O materialismo histórico implica muito mais do que uma contextualização histórica, ou do que uma relação do presente com o passado. Implica, sobretudo, levar em conta as formas de articulação, sempre contraditórias dos elementos da realidade que se pretende investigar.

Outro ponto a ser problematizado refere-se a uma das questões que polemizam os estudiosos da área de trabalho e educação: trata-se da questão da politecnia.

A idéia da politecnia está associada à superação da dicotomia entre trabalho manual e trabalho intelectual. Os estudiosos da área de trabalho e educação partem da suposição de que o sistema capitalista faz o homem perder a sua essência, na medida em que a intensificação da divisão social do trabalho fragmenta o processo de produção entre o trabalho manual e o trabalho intelectual. Nesse processo, o trabalhador se vê mutilado por perder a capacidade de domínio da totalidade do processo de trabalho.

$\mathrm{O}$ argumento principal é que, em uma sociedade baseada na socialização dos meios de produção, o processo produtivo deve ser colocado a serviço de toda a sociedade, daí a suposição de que a divisão entre trabalho manual e trabalho intelectual seria superada, já que ambos formariam uma unidade indissolúvel em qualquer processo produtivo e sua separação teria sido condicionada pelo desenvolvimento do capitalismo. Trata-se, portanto, de adotar a politecnia como um instrumento que possibilite o domínio dos fundamentos científicos das diferentes técnicas que caracterizam o processo produtivo moderno.

Dermeval Saviani discutiu a questão da politecnia em dois textos de referência11. Ele examinou o desenvolvimento histórico por que passa a sociedade apontando para um progressivo e constante avanço das forças produtivas. Dessa forma, supôs que a sociedade capitalista teria alcançado um grau tão elevado de desenvolvimento técnico que estaria prestes a vivenciar o "reino da liberdade". Entretanto, o autor advertiu:

\footnotetext{
“Os frutos desse processo são apropriados privadamente, o que faz com que o usufruto de tempo livre só exista para uma pequena parcela da humanidade, ao passo que os trabalhadores, em que pese o crescimento da riqueza social, são lançados na necessidade de prosseguir em um processo de trabalho forçado" (Saviani, 2003, p. 139).
} 
Nessa contradição é que se insere a idéia de politecnia. Se a escola é um produto da sociedade moderna que necessita universalizar a educação, no sentido de inserir os indivíduos nos processos produtivos; se o modo fragmentado como os conhecimentos são transmitidos na escola é a expressão da própria divisão entre trabalho manual e trabalho intelectual na sociedade capitalista; e se o próprio desenvolvimento do capitalismo atingiu um grau tão elevado a ponto de, por um lado, poder 'liberar' o homem para o lazer, mas, por outro, impedir que a parcela dos trabalhadores possa usufruir do avanço técnico alcançado pelo capitalismo, a idéia da politecnia, para Saviani,

“se esboça nesse contexto, ou seja, a partir do desenvolvimento atingido pela humanidade no nível da sociedade moderna, da sociedade capitalista, já detectando a tendência do desenvolvimento para outro tipo de sociedade que corrija as distorções atuais" (Saviani, 2003, p. 139).

Para Saviani, graças ao constante desenvolvimento das forças produtivas no capitalismo, as transformações da base material atingiram um grau tão elevado, considerado por ele como a Terceira Revolução Industrial, que, mais do que nunca, abrir-se-iam as perspectivas para uma educação politécnica, uma vez que o processo produtivo tende a se tornar cada vez mais autônomo, em função da automação, elevando as exigências de qualificação do trabalhador.

Há questões aqui que devem ser discutidas.

No que concerne à educação escolar, a transmissão do acervo cultural e científico acumulado pela humanidade só poderá constituir-se de fato em uma unidade entre a teoria e a prática na sociedade socialista. Não obstante, é preciso notar que, se as sociedades socialistas devem perseguir a superação da divisão do trabalho e a conquista da unidade entre teoria e prática nos processos produtivos, elas também não poderão deixar de considerar o problema da especialização do trabalhador.

Saes aborda de forma muito apropriada essa questão.

“O Estado socialista, cuja ação econômica e ação administrativa se apóiam solidamente nas conquistas técnicas legadas pelas épocas históricas anteriores e capazes de assegurar um maior domínio do homem sobre a natureza, não pode se orientar pelo propósito de suprimir a divisão do trabalho na sociedade como um todo" (Saes, 2004, p. 81-82).

Essa tese apresentada pelo autor da combinação da politecnia com a necessidade de especialização profissional evita o equívoco de um discurso humanista genérico que tende para a idéia de um homem que faz tudo, ao 
mesmo tempo que resgata a idéia do desenvolvimento multidimensional dos indivíduos.

No tocante às questões aqui discutidas parece ser equivocado supor que, no processo de desenvolvimento das forças produtivas na sociedade capitalista, já se encontrariam os germes que assegurariam as condições necessárias para a superação da dicotomia entre trabalho manual e trabalho intelectual, assim como supor que na sociedade socialista a divisão do trabalho seria superada.

Os mesmos argumentos que justificam o fato de que os elementos cognitivos, oferecidos aos filhos dos trabalhadores pela escola capitalista, só poderão ser redimensionados na sociedade socialista servem também para o fato de que a organização econômica e social da sociedade socialista deverá se calçar nas conquistas técnicas e científicas legadas pela humanidade, mas não poderá desconsiderar a divisão do trabalho na sociedade.

Ainda podemos tocar em mais um problema relacionado à idéia de politecnia apresentada por Saviani. Trata-se da questão da ciência e da tecnologia. O avanço tecnológico atingido na sociedade atual, obedece a uma lógica e a um padrão próprios das sociedades capitalistas ${ }^{12}$. Isso significa que tanto o incremento da tecnologia, quanto a sua utilização não gozam de nenhuma autonomia, mas estão subordinados às relações sociais que as determinam. Portanto, o avanço tecnológico por si só não poderá garantir o 'reino da liberdade' ou a perda da condição da alienação humana; somente em uma sociedade sem antagonismos de classe é que a ciência e a tecnologia deverão adquirir um caráter de reconciliação do homem com a natureza.

No meu entender, esse equívoco se deve à análise unilateral da relação entre trabalho e educação. No caso da politecnia, o que se verifica é que a discussão fica limitada ao avanço das forças produtivas, desconsiderandose as relações sociais que, no capitalismo, são relações de exploração. Portanto, o que faz a classe trabalhadora se subjugar ao capital é o fato de que o capitalismo é um sistema que tem como objetivo primeiro não a produção dos objetos de utilidade social, mas a produção da mais-valia e a reprodução do capital. Ou seja, no capitalismo a produção dos objetos de utilidade social é inteiramente subordinada à da mais-valia, isto é, à produção ampliada do capital, subordinada à exploração e, em decorrência, à produção ampliada do capital.

Sob essas condições, e não pelo fato do trabalhador se alienar dos produtos de seu trabalho, é que a classe burguesa pode exercer seu domínio político e ideológico sobre a classe trabalhadora.

Neste artigo, identifiquei os elementos teóricos que se constituíram na problemática em torno da qual os estudos do GT Trabalho e Educação da Anped foram conduzidos. A partir da identificação destes elementos, 
busquei problematizar algumas questões teóricas e metodológicas concernentes às análises empreendidas.

Para finalizar, é importante ressaltar que, não obstante os problemas teóricos identificados ao longo deste artigo, muitos estudos do campo de trabalho e educação que se apoiaram nos pressupostos elencados conseguiram elucidar os efeitos ideológicos da economia política burguesa na educação. Entretanto, quis mostrar que o problema dessas análises é que elas ficaram restritas ao campo de discussão delimitado pela própria economia política burguesa, dificultando assim a apreensão da relação entre trabalho e educação.

\section{Considerações finais}

O presente artigo teve o objetivo de apreender a problemática sobre a qual os estudos do GT Trabalho e Educação foram conduzidos. Nessa direção, todo o esforço da análise foi para identificar as questões a partir das quais a reflexão teórica dos estudos se desenvolveu.

Para tal, levei em consideração o contexto político e social do período analisado, assim como estabeleci os parâmetros da crítica que me propus realizar em função das questões colocadas naquele momento específico, de modo a compreender a trajetória de formação do pensamento educacional brasileiro crítico a partir das condições específicas naquele momento.

Por esse motivo, tive que passar pelos principais eventos que marcaram a reconstituição do campo educacional no período mais recente da história e verifiquei de que maneira o elemento político presente naquele processo articulou-se ao elemento teórico. Dessa relação, pude constatar que a avaliação que faziam do período de redemocratização do país, no que diz respeito à sua inserção nos processos educacionais, pode ter levado os educadores a um ativismo educacional que se manifestou na sobrevalorização do papel da escola na sociedade capitalista.

A decorrência dessa concepção no plano teórico foi a apropriação enviesada de autores cuja teoria, como foi o caso da teoria da escola capitalista, acabou por ser rejeitada muito mais pela sua inadequação às aspirações políticas e ideológicas dos educadores, expressa na priorização da ação política em detrimento da objetividade do processo histórico, do que propriamente por sua assimilação crítica.

A esse respeito, é importante ressaltar o fato de que muitos dos educadores identificados com a perspectiva crítica da educação brasileira eram oriundos de diferentes denominações religiosas e já traziam uma bagagem teórico-filosófica de acento fenomenológico e existencialista, fato que deve 
ter contribuído muito para que a reflexão sobre o marxismo ficasse atrelada às questões postas por essas correntes teóricas.

A análise do percurso de formação do pensamento educacional brasileiro crítico, assim como as formas de difusão da teoria marxista permitiram entender melhor as condições do surgimento e de conformação do campo de estudos sobre trabalho e educação. Ademais, forneceram pistas para compreender as possibilidades e os limites teóricos e metodológicos deste campo.

Não é objetivo deste artigo fazer um aprofundamento das questões levantadas13, mas tão-somente traçar de forma breve o percurso do GT Trabalho e Educação, de modo a identificar as principais questões que vêm norteando os estudos.

\section{Notas}

1 Professora adjunta da Faculdade de Educação da Universidade Federal do Rio de Janeiro (UFRJ), Rio de Janeiro, Brasil. Doutora em Educação pela Universidade Federal Fluminense (UFF). < ahandfas.bol@uol.com.br >

Correspondência: Universidade Federal do Rio de Janeiro (UFRJ), Faculdade de Educação, Departamento de Didática, Campus da Praia Vermelha, Avenida Pasteur, 250, Botafogo, Rio de Janeiro, Brasil, CEP 22290-240.

2 Inicialmente o GT foi denominado Educação e Trabalho. A inversão para Trabalho e Educação deu-se posteriormente e refere-se às próprias discussões no campo metodológico da relação entre trabalho e educação.

3 Na realidade, a organização do campo educacional no Brasil vem de longa data. Em 1941 foi realizado o I Congresso Nacional de Educação, sob iniciativa de Gustavo Capanema, então ministro da Educação. Todas as iniciativas partiam do Estado, e somente na década de 1970, os educadores passam a se organizar autonomamente. Cumpre ressaltar também que o debate político no campo educacional não se originou na década de 1970; ele está, em parte, vinculado aos embates travados entre os liberais escolanovistas e os socialistas, cada qual com propostas distintas para a educação e para a escola.

4 Foi a editora Cortez, desde a sua criação em meados da década de 1960, a responsável pela edição de grande parte dos livros de autores brasileiros sobre educação.

5 A teoria do capital humano foi uma das correntes do pensamento clássico burguês aplicado à educação. Veremos mais adiante como essa ideologia se tornou objeto de crítica e de elaboração de uma alternativa teórica para os estudiosos do campo de estudos sobre trabalho e educação.

6 Sobre essa questão, Frigotto (apud Yamamoto, 1993) assinala que o estudo das obras de Marx não era feito de forma sistemática, mas se dava muito mais pelo interesse político 
e individual de pesquisadores, uma vez que o marxismo estava ausente dos currículos da pós-graduação, em decorrência do contexto ditatorial do país. Para Frigotto, isso deve ter contribuído para uma leitura doutrinária e pontual da obra de Marx.

7 É provável que tal dificuldade tenha origem na própria maneira de interpretar a obra de Marx. Como se sabe, é idéia corrente que a sua contribuição teria se dado no plano da infra-estrutura da sociedade. Nesse sentido, faltaria à obra de Marx o estudo dos processos superestruturais. Na educação, essa questão pode ter ganhado mais força, na medida em que, segundo essa interpretação, os processos educacionais estariam inseridos na dinâmica superestrutural da sociedade.

8 Devemos considerar essas formas de ler e interpretar tais autores como uma tendência presente na pesquisa educacional, uma vez que inúmeras foram as interpretações de Gramsci que não se limitaram à idéia de que o Estado tem de ser disputado a partir de sua institucionalidade, assim como inúmeras foram as interpretações de Althusser que por meio de análises densas também ultrapassaram o foco das críticas ao problema do 'reprodutivismo'.

9 Nosella chamou a atenção para a 'onda gramsciana' que teria tomado conta dos programas de pós-graduação em educação a partir da década de 1980. Nesse sentido, é interessante observar os seus comentários a respeito da penetração do pensamento de Gramsci nos meios acadêmicos e no meio político. Segundo o autor, nos anos 80, mais de $40 \%$ de teses e dissertações citavam Gramsci. Da mesma forma, após a vitória da oposição nas eleições de 1982, são incontáveis as referências a Gramsci em projetos de secretarias estaduais e municipais de Educação.

10 A primeira edição desse livro data de 1978 e a segunda, que tenho em mãos, de 1980. Daí a referência a 1978 na citação anterior ao livro.

11 Saviani elaborou dois textos sobre a questão da politecnia. O primeiro para o Seminário Choque Teórico, realizado em 1987 e organizado pelo então Politécnico de Saúde Joaquim Venâncio. O evento contou com a participação de diversos educadores e teve como objetivo suscitar as discussões sobre a politecnia, como subsídio para a ação do corpo funcional daquela instituição. Mais recentemente, a Escola Politécnica de Saúde Joaquim Venâncio convidou o autor a retomar o texto sobre a politecnia. Nesse texto, cujo título é O choque teórico da politecnia, Saviani (2003) apresenta uma versão revista do texto de 1987 e retoma a discussão da politecnia, buscando compreendê-la no contexto histórico mais recente.

12 Em um artigo em que discute a questão da tecnologia no socialismo, Wallis (2006) nos leva a questionar a própria viabilidade do avanço tecnológico nas sociedades capitalistas, na medida em que esse avanço estaria subordinado a uma racionalidade própria do capitalismo.

13 Para um maior aprofundamento, consultar Handfas (2006). 


\section{Referências}

CURY, Carlos Roberto Jamil. A propósito de educação e desenvolvimento social no Brasil. Educação \& Sociedade, Campinas, Cedes, Unicamp, n. 9, p. 155-163, 1981.

FRIGOTTO, Gaudêncio. A produtividade da escola improdutiva: um (re)exame das relações entre educação e estrutura econômico-social e capitalista. São Paulo: Cortez, 1999.

HANDFAS, Anita. Uma leitura crítica das pesquisas sobre as mudanças nas condições capitalistas de produção e a educação do trabalhador. Tese de doutorado. Rio de Janeiro: Universidade Federal Fluminense, 2006.

KUENZER, Acacia Zeneida. Educação e trabalho no Brasil: o estado da questão. Brasília: Inep; Santiago: Reduc, 1991.

MARX, Karl. Crítica ao programa de Gotha In: MARX, Karl; ENGELS, Friedrich. Obras escolhidas, v. 2. Rio de Janeiro: Editorial Vitoria, 1961. p. 205-236.

RIBEIRO, Maria Luisa S. (Org.). Educação em debate: uma proposta de pós-graduação. São Paulo: Cortez, 1987.

ROSSI, Wagner Gonçalves. Capitalismo e educação: contribuição ao estudo crítico da economia da educação capitalista. São Paulo: Moraes, 1980.

SAES, Decio. Educação e socialismo. Crítica Marxista, São Paulo, n. 18, p. 73-83, 2004.
SALM, Cláudio. Escola e trabalho. São Paulo: Brasiliense, 1980.

SAVIANI, Dermeval. O choque teórico da politecnia. Trabalho, Educação e Saúde, Rio de Janeiro, v. 1, n. 1, p. 131-152, 2003.

TREIN, Eunice S.; PICANÇO, Iracy S. O GT Trabalho e Educação. Anped. Histórico dos grupos de trabalho. Anped, p. 87-90, set. 1995.

TUMOLO, Paulo Sergio. Metamorfose no mundo do trabalho: revisão de algumas linhas de análise. Revista Educação \& Sociedade, Campinas, Cedes, Unicamp, n. 59, p. 333-350, ago. 1997.

A educação frente às metamorfoses no mundo do trabalho: uma proposta de método de análise. Revista Trabalho e Educação, Belo Horizonte, Nete, UFMG, n. 2, p. 156-170, ago.-dez. 1997.

WALLIS, Victor. Socialismo e tecnologia: uma visão setorial. Crítica Marxista, Rio de Janeiro, Revan, n. 22, p. 55-74, 2006.

YAMAMOTO, Oswaldo Hajime. Educação e a tradição marxista: a produção educacional marxista no Brasil dos anos 70/80. Tese de doutorado. São Paulo: Universidade de São Paulo, 1994.

Recebido em 26/09/2007

Aprovado em 22/11/2007 